Article

\title{
Inonotus obliquus Extracts Decreased Expression of MMP1 mRNA via JNK-AP-1 Axis
}

\author{
Young Joo Kim and Hwa Jun Cha * \\ Department of Beauty \& Cosmetics, Osan University, 45 Cheonghak-ro, Osan, Gyeonggi-do 18119, Korea; \\ michael83@naver.com \\ * Correspondence: hjcha@osan.ac.kr
}

Received: 6 April 2020; Accepted: 13 May 2020; Published: 18 May 2020

\begin{abstract}
Inonotus obliquus, which is parasitic on birch and other trees, is a fungus in the family Hymenochaetaceae. In this study, we investigated whether Inonotus obliquus extracts used in traditional medicine were decreased in the expression of matrix metalloproteinases-1 (MMP-1) in the normal human dermal fibroblasts. As shown in our results, extracts of Inonotus obliquus decreased MMP1 expression in oxidative stress-exposed normal human dermal fibroblasts. Additionally, Inonotus obliquus extracts decreased AP-1 transcriptional activity and phospho-JNK in oxidative stress-exposed normal human dermal fibroblasts. Oxidative stress mediated the elevation of MMP1 mRNA expression and was well regulated by the JNK-AP-1 axis. Therefore, the results suggest that Inonotus obliquus extracts decreased MMP1 mRNA expression by regulating JNK-AP-1 axis. Additionally, Inonotus obliquus extracts have the potential to reduce collagen destruction and the formation of wrinkles and to be used as a cosmetic ingredient.
\end{abstract}

Keywords: Inonotus obliquus extracts; MMP1; human dermal fibroblasts; JNK; AP-1

\section{Introduction}

Skin aging is caused by external and internal factors, such as UV, oxidative and chemical stress [1,2]. A common feature of aging is the creation of wrinkles [3]. Wrinkling is mostly caused by destruction of the extracellular matrix (ECM) in the dermis. ECMs in the dermis are mainly composed of collagen type I, III, VII, and elastin, proteoglycans and fibronectin, especially collagen type I, accounting for more than $70 \%[4,5]$. Therefore, the assembly and disassembly of collagen type I plays an important role in the structure of the dermis. Matrix metalloproteases (MMP1), which is one of the disassemble enzymes, destructs collagen type I [6-8]. MMP1 is highly expressed in natural and photorealistic aging, which induce the destruction of and alterations in the dermal structure [4,5]. Therefore, in the cosmetics field, skin aging is suppressed by maintaining the structure of the ECM through controlling the expression of MMP1 or Collagen type I [9-11]. In photo-ageing, the expression of MMP1 is increased by ultraviolet radiation or reactive oxygen species (ROS), which is a major factor of photo-ageing. Photo-ageing induced phosphorylation of c-Jun N-terminal kinase (JNK), which is one of the MAP kinase families, and then p-JNK activates c-JUN, the main factor of AP-1 complex [12]. Thus, the activation of the AP-1 complex, a transcription factor, increases the expression of MMP1, since MMP1 is one of the target genes of AP-1. The ageing of the skin can be protected through phytochemicals which regulate collagen synthesis and degradation-related genes, such as MMP1 [13]. Therefore, in this study, we investigate that Inonotus obliquus extracts regulates expression of MMP1, and suggest its potential as a functional anti-wrinkle ingredient in cosmetics. 


\section{Materials and Methods}

\subsection{Cell Culture}

Normal human dermal fibroblasts (nHDFs) were purchased and used by Lonza Inc. (Basel, Switzeland). The cell culture was cultured on Dulbeco's Modified Eagle's Medium (DMEM; Gibco, USA) by adding 10\% total bovine serum (FBS; Gibco, Las Vegas, NV, USA) and 10\% P/S solution (Gibco, Las Vegas, NV, USA; penicillin (100 unit/mL), and streptomycin $(100 \mathrm{~g} / \mathrm{mL})$ ). The incubation conditions were incubated at $37{ }^{\circ} \mathrm{C}, 95 \%$ humidity, and $5 \% \mathrm{CO}_{2}$ incubator, and cells between 3 and 15 generations were used in the experiment.

\subsection{Preparation of Inonotus obliquus Extracts}

The dried Inonotus obliquus was blended into powder with a mill. The blended Inonotus obliquus $(5 \mathrm{~g})$ was extracted at $70 \%$ ethanol $(500 \mathrm{~mL})$ with sonication, respectively. After extraction, to separate insoluble substances, the extract was filtered using filter papers (Whatman No. 3; Whatman, Maidstone, $\mathrm{UK})$, and centrifuged for $10 \mathrm{~min}$ at $4{ }^{\circ} \mathrm{C} 5000 \mathrm{rpm}$. The filtered extracts were concentrated and dried using a rotary evaporator (Rotavapor R-100; Buchi, Flawil, Switzerland) and laboratory freeze dryer (ILSHIN, Gyeonggi, Korea). The powder of Inonotus obliquus extracts was dissolved into DMSO, and then Inonotus obliquus extracts were stored at $-20^{\circ} \mathrm{C}$ before use.

\subsection{Cell Viability Assay}

Cell viability was measured using Water Soluble Tetrazolium Salts (WST)-1 assay. In a 96-well plate, $3 \times 10^{3} \mathrm{nHDF}$ were incubated in a DMEM containing $10 \%$ FBS for $24 \mathrm{~h}$. Then, each experimental indicated condition was treated and then incubated again for $24 \mathrm{~h}$. After incubation, EZ-CYTOX ${ }^{\mathrm{TM}}$ (Daeillab, Chungju, Korea) based on a WST-1 assay was added with 10\%, and the cells incubated for $30 \mathrm{~min}$ in $37^{\circ} \mathrm{C}$. After the incubation, the absorbance was measured at a wavelength of $450 \mathrm{~nm}$ with the plate reader (Bio-Rad, Hercules, CA, USA).

\subsection{Quantitative Real Ttime Polymerase Chain Reaction (qRT-PCR)}

Trizol (Invitrogen, Carlsbad, CA, USA) was used to extract total RNA. Total RNA (2 $\mu$ g) was reverse-transcribed using a reverse transcription master premix (Enzynomics, Daejeon, Korea). qRT-PCR was performed using HOT FIRE Pol EvaGreen PCR Mix Plus (Solis BioDyne, Tartu, Estonia). The primer of MMP1 used MMP1 forward primer, 5'-CTTCTGGAGGCAAGGAC-3; MMP1 reverse primer and $5^{\prime}$-TGCCCCCCATTCATTCATTCA-3'; the primer of $\beta$-actin used $\beta$-actin forward primer, $5^{\prime}$-CGACAGGATGCAGAAGGAG-3' and $\beta$-actin reverse primer, 5' -ACATCTGCTGGAAGGTGGA-3' . Normalization was relatively quantified using $\beta$-actin, and the melting curve was measured to determine whether the non-specific band was present.

\subsection{Western Blot}

Cells washed twice with 1X PBS (phosphate-buffered saline), and then were lysed using radio-immuno-precipitation assay (RIPA) lysis buffer (Thermo Scientific, Waltham, MA, USA). After lysis, to remove insoluble substance, lysates were centrifuged at 14,000 rpm for $10 \mathrm{~min}$ at $25{ }^{\circ} \mathrm{C}$. Then, supernatant was separated at whole lysate. The total cellular protein content of lysate is measured using the Pierce ${ }^{\circledR}$ BCA method (Thermo Scientific, Waltham, MA, USA). Whole-cell lysates (20 $\mathrm{\mu g}$ protein each) were separated by 10\% SDS-PAGE (Sodium Dodecyl Sulfate-PolyAcrylamide Gel Electrophoresis), transferred to PVDF (polyvinylidene difluoride membrane; Roche), and probed with primary antibodies (JNK and phosphor-JNK; Santa Cruz Biotechnology, Dallas, TX, USA) and secondary antibodies (anti-mouse-HRP (horseradish peroxidase) and anti-rabbit-HRP; Santa Cruz). Immunodetection was performed using a chemiluminescence 
solution (SuperSignal; Pierce Biotechnology, Waltham, MA, USA), and then the results were normalized with $\beta$-actin.

\subsection{Luciferase Assay}

The genes of Reporter Plasmid (pGL-TRE, $1 \mu \mathrm{g}$ ) and normalization Plasmid (pCMV- $\beta$-gal, $0.2 \mu \mathrm{g}$ ) were tranfected to nHDFs using Hilymix (Dojindo, Kumamoto, Japan) and cultivated for $24 \mathrm{~h}$. Then, each experimental indicated condition was treated. After the treatment of Inonotus obliquus extracts, cultured for $24 \mathrm{~h}$, the cells harvested and lysed into $100 \mu \mathrm{L}$ of $1 \mathrm{X}$ luciferase lysis buffer (Promega, Madison, WI, USA) at $4{ }^{\circ} \mathrm{C}$ for $10 \mathrm{~min}$. The supernatant was then separated and used for luciferase assay. The Luciferase assay was performed using the luciferase agent (Promega) and the luminous intensity was measured using the Luminometer (Veritas, Santa Clara, CA, USA). The Luciferase assay was normalization corrected by measuring the activity of o-Nitrophenyl $\beta$-D-galactopyranoside (ONPG) assay.

\subsection{Statistical Analysis}

The Student $t$-test method was used to determine the statistical significance of the experimental results. It was also determined that the value of $p<0.05$ was significant.

\section{Results}

\subsection{Cytotoxicity Measurement of Inonotus obliquus Extracts in nHDFs}

To identify the cytotoxicity of Inonotus obliquus extracts in nHDFs, cell viability was measured after $24 \mathrm{~h}$ of treating 0, 25, 50, and $100 \mu \mathrm{g} / \mathrm{mL}$ Inonotus obliquus extracts. As shown in Figure 1, cells were found to be non-toxic under $50 \mu \mathrm{g} / \mathrm{mL}$ Inonotus obliquus extracts. Therefore, the efficacy was measured from further experiments using $50 \mu \mathrm{g} / \mathrm{mL}$ Inonotus obliquus extracts.

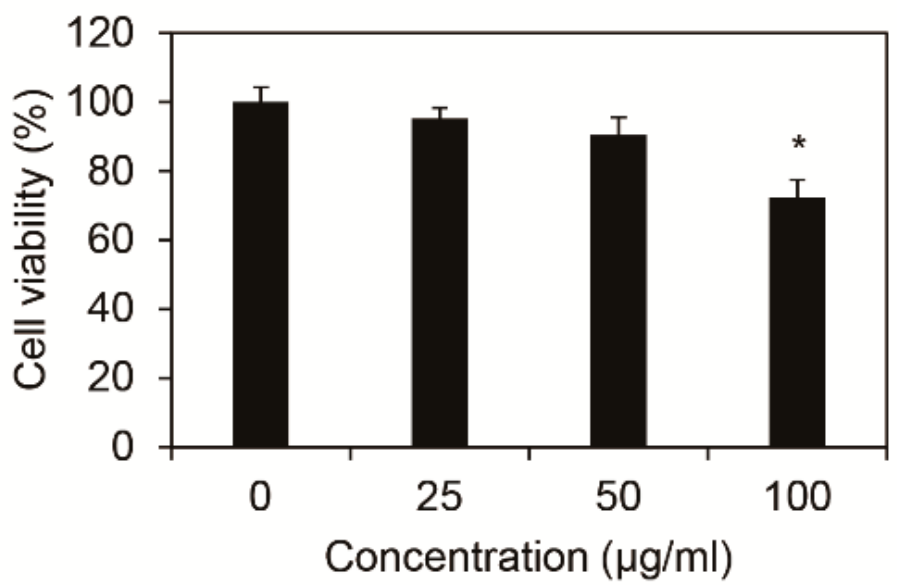

Figure 1. Cytotoxicity of extracts of Inonotus obliquus in human dermal fibroblasts. Effects of Inonotus obliquus extracts on the cell viability were expressed as a percentage of control at the indicated concentrations. Values are mean \pm standard deviation (S.D.) from triplicate experiments. ${ }^{*} p<0.05$ compared with non-treated cells.

\subsection{MMP1 mRNA Expression Suppression of Inonotus obliquus Extracts in nHDFs}

We showed whether Inonotus obliquus extracts decreased MMP1 mRNA expression in nHDFs with $200 \mu \mathrm{M} \mathrm{H}_{2} \mathrm{O}_{2}$. In each condition, cells were harvested and RNA isolated. cDNA was synthesized using isolated RNA, and the expression of MMP1 was verified as qRT-PCR. The results of the experiment revealed that the expression of MMP1 mRNA was increased by 3.20 times $(320.25 \%)$ by $200 \mu \mathrm{M}$ $\mathrm{H}_{2} \mathrm{O}_{2}$ against the control group, as shown in Figure 2. In comparison, $50 \mu \mathrm{g} / \mathrm{mL}$ Inonotus obliquus extracts decreased expression of MMP1 mRNA by 1.92 times (192.34\%) in $200 \mu \mathrm{M} \mathrm{H}_{2} \mathrm{O}_{2}$ exposed 
nHDFs. Therefore, Inonotus obliquus extracts have been confirmed to reduce MMP1 mRNA caused by oxidative stress.

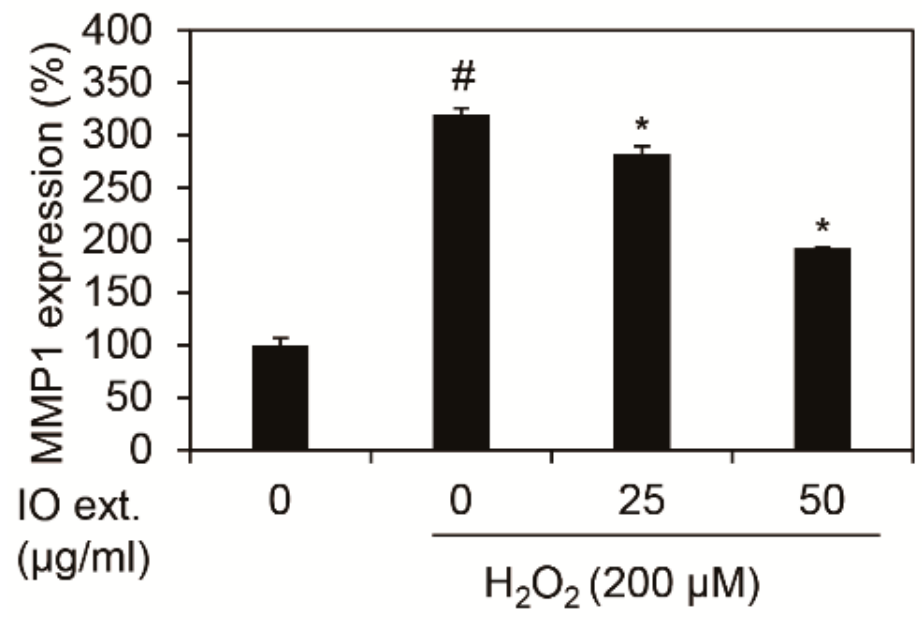

Figure 2. Effects of extracts of Inonotus obliquus on MMP1 mRNA expression in human dermal fibroblasts. Inonotus obliquus extracts decreased MMP1 mRNA expression against $\mathrm{H}_{2} \mathrm{O}_{2}$ treatment at $24 \mathrm{~h}$. MMP1 mRNA expression were normalized to $\beta$-actin. The results are expressed as the mean \pm S.D. from triplicate experiments. \# $p<0.05$ compared with non-treated cells. ${ }^{*} p<0.05$ compared with $200 \mu \mathrm{M} \mathrm{H}_{2} \mathrm{O}_{2}$-treated cells.

\subsection{AP-1 Transcriptional Activity Suppression of Inonotus obliquus Extracts in nHDFs}

The increase in MMP1 mRNA expression due to oxidative stress was induced by phosphorylation at c-Jun, a major component protein of the AP-1 complex. Therefore, we investigated the transcription activity of AP-1 by Inonotus obliquus extracts, which was measured by TPA Response Element (TRE), the DNA-binding site of AP-1 [14,15]. As shown in Figure 3, we demonstrated that $200 \mu \mathrm{M} \mathrm{H}_{2} \mathrm{O}_{2}$ increased 8.26 -fold $(826.36 \%)$ in the transcription activity of the AP-1 complex. However, treating Inonotus obliquus extracts decreased the transcription activity of AP- 1 complex by 3.07 times $(307.46 \%)$ at $24 \mathrm{~h}$ by $50 \mu \mathrm{g} / \mathrm{mL}$ in $200 \mu \mathrm{M} \mathrm{H}_{2} \mathrm{O}_{2}$-exposed nHDFs. Therefore, Inonotus obliquus extracts is verified to reduce the expression of MMP1 by regulating the transcription activity of the AP-1 complex (Figure 3).

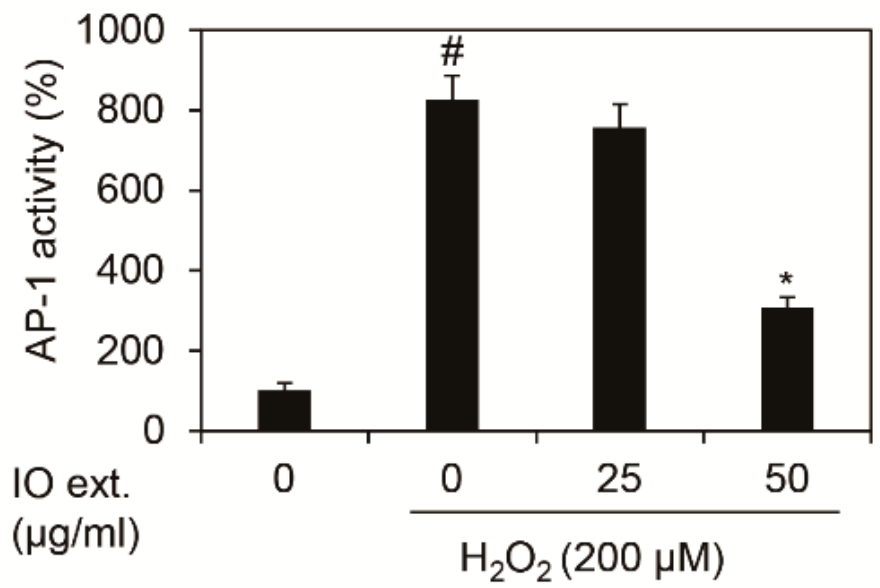

Figure 3. Effects of extracts of Inonotus obliquus on promoter activity of TRE in human dermal fibroblasts. TRE activity was estimated by using TRE-luciferase reporter assay. TRE activity was normalized to $\beta$-galactosidase. The graphs are expressed as the mean \pm S.D. from triplicate experiments. $\# p<0.05$ compared with non-treated cells. ${ }^{*} p<0.05$ compared with $200 \mu \mathrm{M} \mathrm{H}_{2} \mathrm{O}_{2}$-treated cells. 


\subsection{JNK Phosphorylation Suppression of Inonotus obliquus Extracts in nHDFs}

AP-1 activity is regulated by phospho-JNK in oxidative stress. Thus, we showed whether Inonotus obliquus extracts decrease phospho-JNK in $200 \mu \mathrm{M} \mathrm{H}_{2} \mathrm{O}_{2}$ exposed nHDFs [16]. As shown in Figure 4, JNK phosphorylation was elevated by oxidative stress, $200 \mu \mathrm{M} \mathrm{H}_{2} \mathrm{O}_{2}$, and co-treatment of $200 \mu \mathrm{M} \mathrm{H}_{2} \mathrm{O}_{2}$ and Inonotus obliquus extracts showed that phospho-JNK decreased compared to $200 \mu \mathrm{M}$ $\mathrm{H}_{2} \mathrm{O}_{2}$ single treatment at $1 \mathrm{~h}$ (Figure 4).
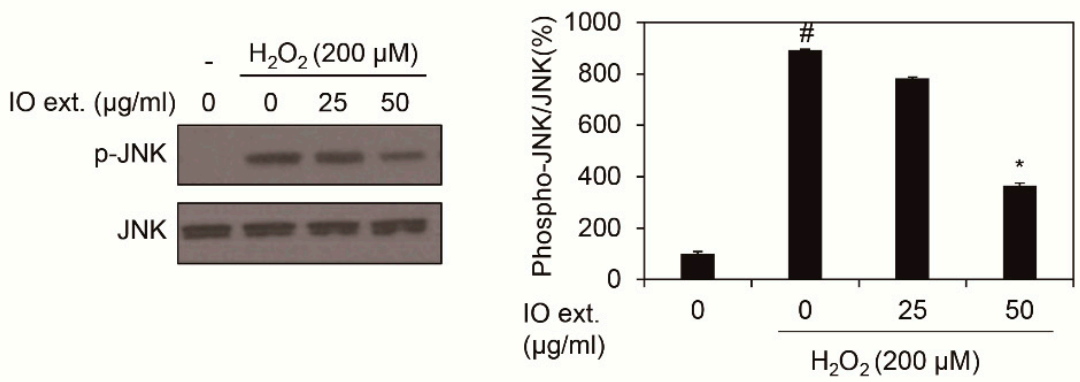

Figure 4. Effects of extracts of Inonotus obliquus on JNK phosphorylation in human dermal fibroblasts. JNK and p-JNK protein expression were assessed by using Western blot assay. $\beta$-Actin served as an internal control, and different concentrations of Inonotus obliquus extracts $(0,25$, and $50 \mu \mathrm{g} / \mathrm{mL})$ were treated in human dermal fibroblasts. JNK band density was measured by Image J software and normalized by band density of $\mathrm{p}$-JNK. The graphs are expressed as the mean \pm S.D. from triplicate experiments. \# $p<0.05$ compared with non-treated cells. * $p<0.05$ compared with $200 \mu \mathrm{M}$ $\mathrm{H}_{2} \mathrm{O}_{2}$-treated cells.

\subsection{JNK-AP-1 Axis Mediated MMP1 mRNA Regulation of Inonotus obliquus Extracts in nHDFs}

To reveal whether Inonotus obliquus extracts down-regulated MMP1 expression using JNK-AP-1 axis, we show MMP1 mRNA, AP-1 activity and p-JNK in time course. As shown in Figure 5, Inonotus obliquus extracts sequentially regulated MMP1 mRNA, AP-1 activity and p-JNK (Figure 5). Overall, Inonotus obliquus extracts regulated the transcription activity of the AP-1 complex by inhibiting JNK, thereby regulating the increased MMP1 expression caused by oxidative stress. Additionally, Inonotus obliquus extracts suggest a potential as an ingredient for anti-wrinkle or anti-aging cosmetics (Figure 5).

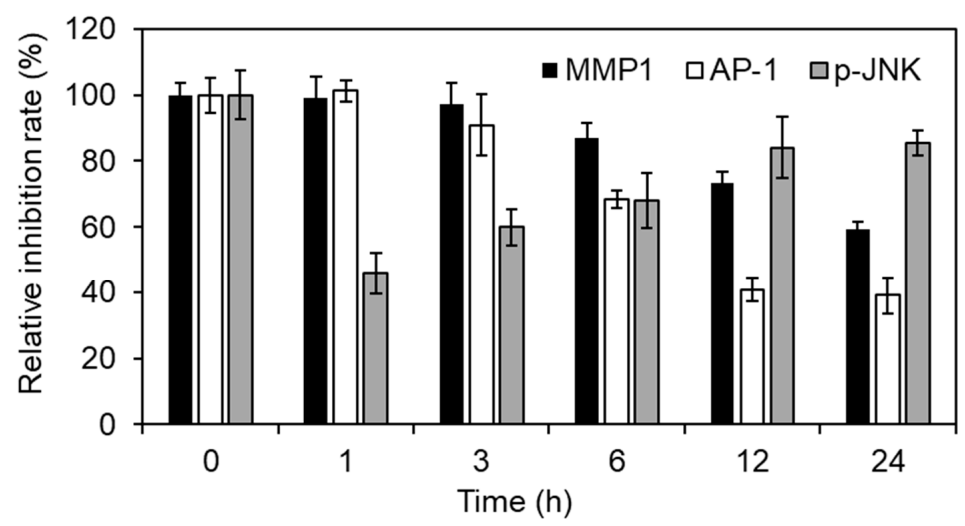

Figure 5. JNK-AP-1 axis mediated MMP1 mRNA regulation of Inonotus obliquus extracts in human dermal fibroblasts. MMP1 mRNA, AP-1 activity and p-JNK was shown in time course. The relative inhibition rate (\%) was evaluated by [1-(200 $\mu \mathrm{M} \mathrm{H}_{2} \mathrm{O}_{2}$-and Inonotus obliquus extracts co-treated cells $/ 200 \mu \mathrm{M} \mathrm{H}_{2} \mathrm{O}_{2}$-treated cells) $] \times 100$. 


\section{Discussion}

In this study, we confirm the anti-aging mechanism of the Inonotus obliquus extracts. Inonotus obliquus is reported therapeutic medicine, with anti-tumor and diuretic properties, such as anti-inflammatory, hepatoprotective, antioxidative, antimicrobial, and antiquorum [17]. In addition, mushrooms, such as Agaricus bisporus, Pleurotus ostreatus, and Lentinula edodes, that are used in cosmetic industry contain bioactive ingredients, such as phenolic acids and ergosterol which regulate the level of cellular Reactive oxygen species (ROS) and sequentially down-regulate AP-1, a transcription factor that promotes collagen and elastin breakdown by up-regulation of the matrix metalloproteinases (MMPs) [18]. As shown in our results, the Inonotus obliquus extracts was found to be non-cellular toxic at concentrations below $50 \mu \mathrm{g} / \mathrm{mL}$ (Figure 1). MMP1 overexpression caused by oxidative stress was decreased by $50 \mu \mathrm{g} / \mathrm{mL}$ Inonotus obliquus extracts at $24 \mathrm{~h}$ (Figure 2). We also found that this regulation of MMP1 was due to reduced transcription activity of AP-1 through a decrease in JNK activity (Figures 3 and 4). In aged skin, MMP1 decomposed the extracellular matrix by degradation of collagen type 1. Especially, MMP1 is elevated by oxidative stress in photo or natural ageing [1,2]. The oxidative stress induced JNK phosphorylation, and then phospho-JNK elevates the transcriptional activity of AP-1, which is finally upregulated by MMP1 expression [16,19]. Thus, our results suggest that Inonotus obliquus extracts decrease MMP1 mRNA expression by downregulating AP-1 transcriptional activity and JNK phosphorylation [14,15]. Moreover, through the results of this study, we identified that the Inonotus obliquus extracts are a cosmetic material that have the potential to control the decomposition of the collagen by reducing the expression of MMP1, and thus presents a possibility as a new functional cosmetic ingredient for reducing wrinkles by revealing clinical anti-wrinkle effects in further study.

\section{Conclusions}

Treatment with Inonotus obliquus extracts attenuated MMP1 expression in nHDFs, which is determined by qRT-PCR. Furthermore, Inonotus obliquus extracts down-regulated AP-1 transcriptional activity and phosphorylation of JNK. These data collectively indicate that Inonotus obliquus extracts are potent inhibitors of skin aging.

Author Contributions: Conceptualization, Y.J.K. and H.J.C.; methodology, Y.J.K. and H.J.C.; validation, Y.J.K. and H.J.C.; formal analysis, Y.J.K. and H.J.C.; investigation, Y.J.K. and H.J.C.; writing-original draft preparation, Y.J.K. and H.J.C.; writing-review and editing, Y.J.K. and H.J.C. All authors have read and agreed to the published version of the manuscript.

Funding: This research was supported by Osan University in 2019 (Kim, YJ) and Basic Science Research Program through the National Research Foundation of Korea (NRF) funded by the Ministry of Education (2017R1D1A1B03028380).

Conflicts of Interest: The authors declare no conflict of interest.

\section{References}

1. Quan, T.; Qin, Z.; Xia, W.; Shao, Y.; Voorhees, J.J.; Fisher, G.J. Matrix-degrading metalloproteinases in photoaging. J. Investig. Dermatol. Symp. Proc. 2009, 14, 20-24. [CrossRef] [PubMed]

2. Shin, J.W.; Kwon, S.H.; Choi, J.Y.; Na, J.I.; Huh, C.H.; Choi, H.R.; Park, K.C. Molecular Mechanisms of Dermal Aging and Antiaging Approaches. Int. J. Mol. Sci. 2019, 20, E2126. [CrossRef] [PubMed]

3. Fisher, G.J.; Kang, S.; Varani, J.; Bata-Csorgo, Z.; Wan, Y.; Datta, S.; Voorhees, J.J. Mechanisms of Photoaging and Chronological Skin Aging. Arch. Dermatol. 2002, 138, 1462-1470. [CrossRef] [PubMed]

4. Bateman, J.F.; Lamandé, S.R.; Ramshaw, J.A.M. Collagen superfamily. In Extracellular Matrix; Comper, W.D., Ed.; Harwood Academic Publishers: Amsterdam, The Netherlands, 1996; pp. 22-67.

5. Uitto, J. Connective tissue biochemistry of the aging dermis. Age-associated alterations in collagen and elastin. Dermatol. Clin. 1986, 4, 433-446. [CrossRef]

6. Chung, H.Y.; Kim, H.J.; Shim, K.H.; Kim, K.W. Dietary modulation of prostanoid synthesis in the aging process: Role of cyclooxygenase-2. Mech. Aging Dev. 1999, 111, 97-106. [CrossRef] 
7. Coulomb, B.; Dubertet, L.; Merrill, C.; Touraine, R.; Bell, E. The collagen lattice: A model for studying the physiology, biosynthetic function and pharmacology of the skin. Br. J. Dermatol. 1984, 27, 83-87. [CrossRef] [PubMed]

8. Fisher, G.J.; Voorhees, J.J. Molecular mechanisms of photoaging and its prevention by retinoic acid: Ultraviolet irradiation induces MAP kinase signal transduction cascades that induce AP-1-regulated matrix metalloproteinases that degrade human skin in vivo. J. Investig. Dermatol. Symp. Proc. 1998, 3, 61-68. [PubMed]

9. Varani, J.; Spearman, D.; Perone, P.; Fligiel, S.E.G.; Datta, S.; Wang, Z.Q.; Voorhees, J.J. Inhibition of type I procollagen synthesis by damaged collagen in photoaged skin and by collagenase-degraded collagen in vitro. Am. J. Pathol. 2001, 158, 931-942. [CrossRef]

10. Di, L.C.; Pei, Y.; Travers, J.B. Augmentation of ultraviolet B radiation-induced tumor necrosis factor production by the epidermal platelet-activating factor receptor. J. Biol. Chem. 1999, 274, 26917-26921.

11. Angel, P.; Szabowski, A.; Schorpp-Kistner, M. Function and regulation of AP-1 subunits in skin physiology and pathology. Oncogene 2001, 20, 2413-2423. [CrossRef] [PubMed]

12. Fisher, G.J.; Wang, Z.Q.; Datta, S.C.; Varani, J.; Kang, S.; Voorhees, J.J. Pathophysiology of premature skin aging induced by ultraviolet light. N. Engl. J. Med. 1997, 337, 1419-1428. [CrossRef] [PubMed]

13. Dasgupta, J.; Kar, S.; Liu, R.; Joseph, J.; Kalyanaraman, B.; Remington, S.J.; Chen, C.; Melendez, J.A. Reactive oxygen species control senescence-associated matrix metalloproteinase-1 through c-Jun-N-terminal kinase. J. Cell. Physiol. 2010, 225, 52-62. [CrossRef] [PubMed]

14. Risse, G.; Jooss, K.; Neuberg, M.; Brüller, H.J.; Müller, R. Asymmetrical recognition of the palindromic AP1 binding site (TRE) by Fos protein complexes. EMBO J. 1989, 8, 3825-3832. [CrossRef]

15. Park, K.K.; Jung, E.; Chon, S.K.; Seo, M.; Kim, H.W.; Park, T. Finding of TRE (TPA responsive element) in the sequence of human taurine transporter promoter. Adv. Exp. Med. Biol. 2003, 526, 159-166. [PubMed]

16. Leppä, S.; Saffrich, R.; Ansorge, W.; Bohmann, D. Differential regulation of c-Jun by ERK and JNK during PC12 cell differentiation. EMBO J. 1998, 17, 4404-4413. [CrossRef] [PubMed]

17. Glamočlija, J.; Ćirić, A.; Nikolić, M.; Fernandes, Â.; Barros, L.; Calhelha, R.C.; Ferreira, I.C.; Soković, M.; van Griensven, L.J. Chemical characterization and biological activity of Chaga (Inonotus obliquus), a medicinal "mushroom". J. Ethnopharmacol. 2015, 162, 323-332. [CrossRef] [PubMed]

18. Taofiq, O.; Heleno, S.A.; Calhelha, R.C.; Alves, M.J.; Barros, L.; Barreiro, M.F.; González-Paramás, A.M.; Ferreira, I.C. Development of Mushroom-Based Cosmeceutical Formulations with Anti-Inflammatory, Anti-Tyrosinase, Antioxidant, and Antibacterial Properties. Molecules 2016, 21, E1372. [CrossRef] [PubMed]

19. Karin, M. The regulation of AP-1 activity by mitogenactivated protein kinases. J. Biol. Chem. 1995, 270, 16483-16486. [CrossRef]

(C) 2020 by the authors. Licensee MDPI, Basel, Switzerland. This article is an open access article distributed under the terms and conditions of the Creative Commons Attribution (CC BY) license (http://creativecommons.org/licenses/by/4.0/). 